\title{
A study on the locus of control in patients with depression and anxiety
}

\author{
Namrata Joshi \\ Assistant Professor (CHB), Department of Psychology, R.D. National College, Mumbai. \\ E-mail - namratajoshis@yahoo.com
}

\begin{abstract}
Background: The present study was conducted to study the two clinical populations- patients with Depression and Anxiety in the context of their attribution style - locus of control. It is common to have a loss or reduced locus of control in these disorders.

Methods: Depression was defined as the diagnostic criteria as stated in the DSM IV-TR manual where as those suffering from anxiety were considered from the following areas with the help of DSM IV -TRSocial Anxiety Disorder, Generalized Anxiety Disorder, Specific Phobia, Agoraphobia. The sample consisted of two groups of the patients each having 30 participants from various mental health setups like B.Y.L. Nair hospital, G.T. Hospital, L.T.M.C. hospital. One group consisted of patients diagnosed with Depression and the other group was of patients diagnosed with Anxiety. Each of the participants was given the Levenson's Locus of Control Inventory where only the internal and external scores (summing of Powerful others and chance scale) was considered.

Results: The statistical analysis of the External Locus of Control between patients with depression (Means= 48.57; $\mathrm{SD}=12.07$ ) and anxiety (Mean= 43.37; $\mathrm{SD}=7.42$ )showed statically significant difference. That is, the participants diagnosed with depression from above mentioned sample were higher in measured external locus of control compared to the participants diagnosed with anxiety disorder. On the other hand, there was no significant difference found in Internal Locus of Control between patients with Depression $(\mathrm{Mean}=21.83 ; \mathrm{SD}=4.84)$ and Anxiety (Mean= 21.37; $\mathrm{SD}=3.28)$.

Conclusion: External locus of control may be significantly impaired in patients with depression when compared to patients with anxiety while internal locus of control may show no difference
\end{abstract}

Keywords: anxiety, depression, DSM IVTR, locus of control.

(Received $-21^{\text {st }}$ April 2016, Peer Review done $-3^{\text {rd }}$ June 2016, Accepted $-19^{\text {th }}$ June 2016)

\section{INTRODUCTION}

Major Depressive Disorder is described as the emotional experiences that in a given range - episodes of sadness to a chronic and profound disinterest or inability to experience pleasure in any given activity [1]. Clinically speaking, depression can be classified into three categories- mild, moderate and severe based on the number and severity of the symptoms [2]. Anxiety disorders generally continue to show symptoms for many years with its significant personal distress, reduced quality of life, increased morbidity and mortality, and a substantial economic burden [3]. It becomes an issue when its duration, intensity or frequency begins to cause distress to the level that it interferes with a person's functioning [4]. Rotter defined locus of control as a "generalized expectancy of internal versus external control over behavior outcomes" He viewed locus of control as unidimensional - internal and external [5]. Levenson developed another model in 1973 with three dimensions: Internality, Chance, and Powerful Others [6]. If the behavior is viewed in 
the control of self it is viewed as Internal. If the outcome of the behavior is perceived outside one's influence (include luck, fate chance) it is called as External [7]. In a study, it was found that socially anxious individuals obtained high 'powerful others' subscale scores on Levenson's locus of control scale [8].

The linkage between depression and locus of control has been evident in literature. Authors [1] conducted a research study to establish estimates of the prevalence of depressive symptoms, and their correlates with locus of control and satisfaction with life among undergraduate students in Hashemite University (HU) Jordan. Who completed the Multidimensional Health Locus of Control Scale (MHLC), the Satisfaction with Life Scale (SLS), and the Center for Epidemiologic Studies Depression Scale (CES-D). Results stated that depressive symptoms were observed in a great number in the University Students. Further statistical analysis showed Positive relationship between the Chance factor of External Locus of Control and Depression. It was also found that there was no relationship between Powerful others factor of External locus of control and depression.

Other researchers [9] undertook a longitudinal research with the aim to study patients with severe mental disorders and to identify if their outlook towards life events (LOC) and its relation to depression. The results indicated that external locus of control was simultaneously related to depressed mood and behavior. The data tend to support much of the research done on locus of control and depression, which generally indicates that externality, is linked to depression [10].

While understanding the relationship between these two constructs (Depression and Externality in Locus of Control) which are so closely studied in literature, it is difficult to state the cause and effect [9]. In another study [11], the focus was on correlation of depression, age and locus of control. It was found that Depression (measured on the Beck Depression Inventory) and locus of control (measured on Rotter's Internal-External questionnaire) were correlated highly. Age was correlated negatively with locus of control scores and positively with depression. When the age wasnot considered, it was noticed that the correlation between external locus of control and depression increased.

Jaswal \& Diwan [12] aimed to assess the relationship between depression and locus of control. They studied 139 girls through incidental sampling who completed Levenson's Locus of Control and IPAT depression Scale. It was found that the scores on IPAT Depression were found to be negatively related to scores on Levenson's Locus of Control scale for Internality. On the other hand, depression was found to be positively related to the Powerful Others, and Chance locus of control Scales.

In a study researchers [13], examined the mediating effect of self-esteem on the relationship between locus of control and depression among Chinese University students. In all, 457 students (232 men and 225 women) completed measures of locus of control, self-esteem, and depression. Correlational analyses indicated that external locus of control was related to self-esteem and depression, and self-esteem was related to depression. Structural equation modeling analysis showed that self-esteem partially mediated the influence of locus of control on depression. Based on past research and the literature, the present study was designed to examine the effects of clinically depressive symptoms, anxiety disorders on attribution styles through the measured locus of control.

\section{METHODOLOGY}

This study aimed at analyzing the difference, if any, in the locus of control among patient diagnosed with depression and anxiety. Attribution style and the outlook towards life and situation is one of the vital components in relation to Depression and Anxiety. These constructs in relation to Locus of Control are extensively studied in the literature. Hence, the objective of the study was to study and compare each attribution style between patients with Depression and Anxiety. That is, comparing the Externalityof Locus of Control between patients with depression and those diagnosed with anxiety. Similarly, comparing the Internality of Locus of Control between patients with depression and those diagnosed with anxiety 


\section{Hypothesis}

There is a difference in the measured external locus of control among patients suffering from depression and those suffering from anxiety. There is a difference in the measured internal locus of control among patients suffering from depression and those suffering from anxiety.

\section{Independent Variable}

Level 1- Anxiety (The diagnostic group of anxiety (social phobia, generalized anxiety disorder, specific phobia, agoraphobia) can be defined as the criteria fulfilled as given in the Diagnostic and Statistical Manual - IV- Text Revision (DSM- IV TR))

Level 2- Depression (The diagnostic group of depression (unipolar depression) can be defined as the criteria fulfilled as given in the Diagnostic and Statistical Manual - IV- Text Revision (DSM- IV TR)

\section{Dependent Variable}

Locus of control as measured by a Self report measure - Levenson's Locus of Control scale.

\section{Sample}

Non- probability sampling

30 Adults (Age group- 20 to 40 years) diagnosed with depression. Sample included in the study were participants who meet criteria for mood disorders as per the criteria in DSM- IV TR.

30 Adults (Age group- 20 to 40 years) diagnosed with anxiety. Sample included in the study were the participants who meet criteria for anxiety disorders as per the criteria in DSM- IV TR.

\section{Tools used in the study}

Levenson's Multi- dimensional locus of control: A scale developed to measure the internal and two external dimensions (chance and powerful others) of the locus of control concept. Levenson's Multidimensional locus of control has 24 items, with the score ranging from -3 to +3 . The items are divided into 3 categories of internal powerful others and chance scale. Total responses for the items listed for each of the three parts of the scale are scored and +24 are added to each of the three totals. However, in this study Externality was not bifurcated into Powerful other or chance scale. Both of these factors were combined and formed into one score of External Locus of Control. Overall, two scores from each participant was obtained- Internal and External Locus of Control [14].

The participants were the inpatient and the outpatients in the B.Y.L. Nair hospital, L.T.M.C. hospital, G.T. hospital. The Locus of Control Scale was administered to each of the participants. All the participants were given consent form before giving the questionnaire. They were given the related instructions regarding the questionnaire. The participants were debriefed after the questionnaire was filled. After which the statistical procedures was undertaken.

\section{STATISTICAL ANALYSIS}

The two tailed t-test, for one independent variable having two levels was used to compare the scores obtained from both the questionnaires by both the group of participants.

\section{RESULTS}

As seen in table 1 the obtained mean score and the standard deviation in terms of external locus of control in the patients with depression was 48.57 and 12.07 respectively. Whereas, the obtained mean score and the standard deviation for the construct external locus of control in the patients with anxiety was 43.37 and 7.42 respectively. The mean score for the patients suffering from depression was higher than the patients with anxiety disorder. Intermediate values used in calculations is $\mathrm{t}_{(58)}=2.070, \mathrm{p}<0.05$ level. This states that the two diagnostic groups (anxiety and depression) differ, statistically, in terms of the measured external locus of control. Thus, the results are consistent with the proposed hypothesis, that is, - There isa difference in the obtained scores of external locus of control among patients with depression and those patients with anxiety. Hence, we accept the alternate hypothesis.

Focusing on the last hypothesis of the research, that is, there is a difference in the obtained scores of internal locus of control among patients with depression as well as patients with anxiety. Table 1 includes 
the obtained internal locus of control scores from the patients suffering from depression and those suffering from anxiety. The obtained mean score for internal locus of control in the patients with depression was 21.83. The obtained Standard deviation for internal locus of control in patients with depression was 4.84 . On the other hand, the obtained mean score for internal locus of control in the patients with anxiety disorder was 21.37 and the standard deviation for the internal locus of control in the patients with anxiety were 3.28. The mean score for the patients with depression was slightly higher than the patients with anxiety disorder. Intermediate values used in calculations $\mathrm{t}_{(58)}=0.44$, not significant. By conventional criteria, this difference is considered to be statistically not significant. This states that the two diagnostic groups (anxiety and depression) did not differ, statistically, in terms of the measured internal locus of control. Thus, the results are inconsistent with the proposed hypothesis, that is, - There is no difference in the obtained scores of internal locus of control among patients with depression as well as patients with anxiety. Hence, we reject the alternate hypothesis and accept the null hypothesis, that is, there is a difference in the obtained scores of internal locus of control among patients with depression as well as patients with anxiety.

Table 1 - Locus of control scores across both groups

\begin{tabular}{|c|c|c|c|}
\hline $\begin{array}{c}\text { Groups } \\
(\mathrm{n}=30 \text { in each group })\end{array}$ & $\begin{array}{c}\text { Scores } \\
\text { Mean } \pm \text { SD }\end{array}$ & t value & $\mathrm{p}$ value \\
\hline $\begin{array}{c}\text { External LOC } \\
\text { Depression } \\
\end{array}$ & $48.57 \pm 12.07$ & \multirow{2}{*}{$\begin{array}{c}2.35 \\
(\mathrm{df}=58)\end{array}$} & \multirow[t]{2}{*}{$0.022^{*}$} \\
\hline $\begin{array}{l}\text { External LOC } \\
\text { Anxiety } \\
\end{array}$ & $43.37 \pm 7.42$ & & \\
\hline $\begin{array}{c}\text { Internal LOC } \\
\text { Depression }\end{array}$ & $21.83 \pm 4.84$ & \multirow{2}{*}{$\begin{array}{c}0.44 \\
(d=58)\end{array}$} & \multirow[t]{2}{*}{$0.6616 \mathrm{NS}$} \\
\hline $\begin{array}{c}\text { Internal LOC } \\
\text { Anxiety } \\
\end{array}$ & $21.37 \pm 3.28$ & & \\
\hline
\end{tabular}

\section{DISCUSSION}

As analyzed and seen, the Externality of locus of control is related to depression more as compared to Anxiety. That is, those diagnosed with depression showed more Externality in their locus of control as compared to those diagnosed with anxiety. Moreover, when it comes to differences in the internality of the locus of control the two groups (those diagnosed with depression and anxiety) were more or less similar (with no significant difference). The possible reason for the occurrence of no difference in terms of Internality of the locus of control, depression and anxiety could be that both the groups tend to blame or hold themselves responsible for the consequences, and internalize to an extent.

A study conducted [15] quoted that there were no significant differences between the Internal scale scores of the Levenson's Locus of Control Scale and of those in the different anxiety and depressive disorder groups and the Control Group. But, patients with Major Depression, Social Phobia, or Mixed Anxiety Disorder had significantly higher Powerful others scale scores of the Levenson's Locus of Control than the Control Group. Patients with Major Depression, Panic Disorders, Social Phobia, and Mixed Anxiety Disorder had higher Chance scale scores in the Levenson's Locus of Control than the Control Group. The Obsessive Compulsive Disorder patients had the lowest Powerful others scale scores and Chance scale scores in the Levenson's Locus of Control scale when compared to other groups. However no significant difference found between the Obsessive Compulsive Disorder patients and Control Group.

Taking into consideration the patients diagnosed with depression, their belief that they are going to fail no matter the amount of efforts they put forth, keeps them away from the success and improvement [9]. Their belief of having no control over things becomes more prominent leading to hopelessness and inability to influence the outcomes. This can be a probable justification to the obtained results for the variable Locus of Control. Depression is one of the most frequently studied concepts in relation to a more external locus 
of control. The relation between a more external locus of control and increased depression has been supported by studies examining college students [16], cancer patients [17]. In the longitudinal study by Harrow and others [9], the relation between Locus of Control and Depression was significant for the overall sample $(\mathrm{t}=2.54,124 \mathrm{df}, \mathrm{p}=.01)$ indicating that patients who were more External in their Locus of Control at the 4.5-year follow ups were likely, concurrently, to be more depressed, while those patients who were more Internal on Locus of Control were likely, concurrently, to be less depressed at the 4.5 year follow. The present study was limited by a small sample size and further studies in this direction are warranted.

\section{REFERENCES}

1. Zawawi JA, Hamaideh SH. Depressive symptoms and their correlates with locus of control and satisfaction with life among Jordanian college students. Eur J Psychol 2009;5(4):71-103.

2. Enns MW, Cox BJ. Personality dimensions and depression: review and commentary. Can J Psychiatry 1997;42(3):274-84.

3. Andlin-Sobocki P, Wittchen HU. Cost of anxiety disorders in Europe. Eur J Neurol 2005;12(s1):39-44.

4. Simos G, Hofmann SG. CBT for anxiety disorders: a practitioner book. John Wiley \& Sons; 2013.

5. Phares EJ. Locus of control in personality. General Learning Press; 1976.

6. Smith PB, Trompenaars F, Dugan S. The Rotter locus of control scale in 43 countries: A test of cultural relativity. Int J Psychol 1995;30(3):377-400.

7. Rotter JB. Internal versus external control of reinforcement: A case history of a variable. Amer Psychol 1990;45(4):489-93.

8. Cloitre M, Heimberg RG, Liebowitz MR, Gitow A. Perceptions of control in panic disorder and social phobia. Cogn Ther Res 1992;16(5):569-77.

9. Harrow M, Hansford BG, Astrachan-Fletcher EB. Locus of control: Relation to schizophrenia, to recovery, and to depression and psychosis-A 15-year longitudinal study. Psychiatr Res 2009;168(3):186-92.

10. Daniels K, Guppy A. Stressors, locus of control, and social support as consequences of affective psychological well-being. J Occup Health Psychol 1997;2(2):156-62.

11. Costello EJ. Locus of control and depression in students and psychiatric outpatients. J Clin Psychol 1982;38(2):340-3.

12. Jaswal S, Dewan A. The relationship between locus of control and depression. J Personal Clin Stud 1997;13:25-8.

13. Chak K, Leung L. Shyness and locus of control as predictors of internet addiction and internet use. Cyberpsychol Behav 2004;7(5):559-70.

14. Levenson H. Multidimensional locus of control in psychiatric patients. J Consult Clin Psychol 1973;41(3):397-404.

15. Ward C, Kennedy A. Locus of control, mood disturbance, and social difficulty during cross-cultural transitions. Int J Intercult Relat 1992;16(2):175-94.

16. Twenge JM, Zhang L, Im C. It's beyond my control: A cross-temporal meta-analysis of increasing externality in locus of control, 1960-2002. Personal Soc Psychol Rev 2004;8(3):308-19.

17. Judge TA, Erez A, Bono JE, Thoresen CJ. Are measures of self-esteem, neuroticism, locus of control, and generalized self-efficacy indicators of a common core construct? J Personal Soc Psychol 2002;83(3):693-710.

\footnotetext{
Acknowledgements - Nil

Source of Funding - Nil

Conflict of Interest - Nil
} 